\title{
The 'ins and outs' of colonoscopy at Wits Donald Gordon Medical Centre, South Africa: A practice audit of the outpatient endoscopy unit
}

\author{
C Bouter, ${ }^{1}$ BHSc; P Barrow, ${ }^{1,2}$ MB BCh, DCH (SA), FCP (SA), Cert Gastroenterology (SA); D Bizos, ${ }^{1,3,4}$ MB BCh, MMed (Surg), FCS (SA); \\ B Bobat, ${ }^{1}$ MB ChB, Dip HIV Man (SA), FCP (SA), Cert Gastroenterology (SA); J Devar, ${ }^{1,5}$ MB BCh, FCS (SA), Cert Gastroenterology (SA) Surg; \\ N Harran, ${ }^{1}$ MB BCh, MMed (Surg), FCS (SA), Cert Gastroenterology (SA) Surg; C Joseph, ${ }^{1,3}$ MB BCh, DA (SA), FCS (SA), Cert Gastroenterology (SA); \\ A Mahomed, ${ }^{1,2}$ MB BCh, FCP (SA), Cert Gastroenterology (SA); J Oettle, ${ }^{1}$ BSc Hons, MB BCh, FRCS (Ed); J Ramos, ${ }^{1,3}$ MB BCh, FCS (SA); \\ M Seabi, ${ }^{1,2} \mathrm{MB}$ ChB, FCP (SA), Cert Gastroenterology (SA), MMed (Int Med); G Kgabage, ${ }^{1} \mathrm{RN}$; P Gaylard, ${ }^{6} \mathrm{PhD}$; D Surridge, ${ }^{1,5} \mathrm{MB} \mathrm{ChB}$, \\ FCS (SA), MMed (Surg), Cert Gastroenterology (SA) Surg; H Etheredge, ${ }^{1,2}$ PhD; J Fabian, ${ }^{1,2}$ MB BCh, FCP (SA), Cert Nephrology (SA); \\ D Lutrin, ${ }^{1,3} \mathrm{MB} B C h, \mathrm{DA}(\mathrm{SA}) ; \mathrm{K}$ Karlsson, ${ }^{1} \mathrm{MB}$ ChB, MRCP (UK), FCP (SA)
}

\author{
${ }^{1}$ Wits Donald Gordon Medical Centre, University of the Witwatersrand, Johannesburg, South Africa \\ ${ }^{2}$ Department of Internal Medicine, Faculty of Health Sciences, University of the Witwatersrand, Johannesburg, South Africa \\ ${ }^{3}$ Department of Surgery, Faculty of Health Sciences, University of the Witwatersrand, Johannesburg, South Africa \\ ${ }^{4}$ Surgical Gastroenterology Unit, Charlotte Maxeke Johannesburg Academic Hospital, Johannesburg, South Africa \\ ${ }^{5}$ Gastroenterology Unit, Chris Hani Baragwanath Academic Hospital, Johannesburg, South Africa \\ ${ }^{6}$ Data Management and Statistical Analysis (DMSA), Johannesburg, South Africa
}

Corresponding author: C Bouter (carolynbouter@outlook.com)

\begin{abstract}
Background. In South Africa, there are no national guidelines for the conduct or quality assessment of colonoscopy, the gold standard for investigation and diagnosis of bowel pathology.

Objectives. To describe the clinical profile of patients and evaluate the practice of colonoscopy using procedural quality indicators at the Wits Donald Gordon Medical Centre (WDGMC) outpatient endoscopy unit (OEU).

Methods. We conducted a prospective, clinical practice audit of colonoscopies performed on adults ( $\geq 18$ years of age). A total of 1643 patients were included in the study and variables that were collected enabled the assessment of adequacy of bowel preparation, length of withdrawal time and calculation of caecal intubation rate (CIR), polyp detection rate (PDR) and adenoma detection rate (ADR). We stratified PDR and ADR by sex, age, population group, withdrawal time and bowel preparation. CIR, PDR and ADR estimates were compared between patient groups by the $\chi^{2}$ test; Fisher's exact test was used for $2 \times 2$ tables. A $p$-value $<0.05$ was used. Benchmark recommendations by the American Society for Gastrointestinal Endoscopy (ASGE)/American College of Gastroenterology (ACG) Task Force on Colorectal Cancer (CRC) were used in this audit to assess individual endoscopist performance and that of the endoscopy unit as a whole.

Results. The mean age of patients was 55.7 (standard deviation (SD) 14.4; range 18 - 91) years, $60 \%$ were female, and the majority (75.5\%) were white. Of the outpatients, $77.6 \%$ had adequate bowel preparation (ASGE/ACG benchmark $\geq 85 \%$ ). The CIR was $97.0 \%$ overall, and screening colonoscopy was $96.3 \%$ (ASGE/ACG benchmark $\geq 90 \%$ overall and $\geq 95 \%$ for screening colonoscopies). The median withdrawal time for negative-result screening colonoscopies was 5.7 minutes (interquartile range (IQR) 4.2 - 9.3; range 1.1 - 20.6) (ASGE/ACG benchmark $\geq 6$ minutes), and PDR and ADR were $27.6 \%$ and $15.6 \%$, respectively (ASGE/ACG benchmark ADR $\geq 25 \%$ ). We demonstrated a $23.7 \%$ increase in PDR and $14.1 \%$ increase in ADR between scopes that had mean withdrawal times of $\geq 6$ minutes and $<6$ minutes, respectively. Although the number of black Africans in the study was relatively small, our results showed that they have similar ADRs and PDRs to the white population group, contradicting popular belief.

Conclusions. The WDGMC OEU performed reasonably well against the international guidelines, despite some inadequacy in bowel preparation and lower than recommended median withdrawal times on negative-result colonoscopy. Annual auditing of clinical practice and availability of these data in the public domain will become standard of care, making this audit a baseline for longitudinal observation, assessing the impact of interventions, and contributing to the development of local guidelines.
\end{abstract}

S Afr Med J 2020;110(12):1186-1190. https://doi.org/10.7196/SAMJ.2020.v110i12.14419

Colonoscopy is regularly used for investigation of bowel pathology and has become the gold standard for screening and diagnosis of colorectal cancer (CRC). ${ }^{[1]}$ The procedure has diagnostic and therapeutic benefits, such as direct visualisation of the entire colon and removal of precancerous polyps, which is associated with a lowered risk of CRC. ${ }^{[2]}$ Colonoscopy is a skill-intensive procedure and poses a risk to the patient, even if performed by a trained endoscopist in an appropriate setting. ${ }^{[1]}$ Therefore, there is a need for standardised practice and regular audit of endoscopists to ensure consistent, high-quality care. ${ }^{[3]}$

Based on the 'adenoma-carcinoma sequence' hypothesis for developing CRC, screening and surveillance colonoscopy aim to detect and remove polyps, particularly adenomatous polyps, with the intention of reducing the incidence of CRC. ${ }^{[4]}$ Therefore, the polyp detection rate (PDR) and adenoma detection rate (ADR) are two key indicators of the quality of endoscopy. Other measurable 
factors, such as adequate bowel preparation, reaching the caecum or terminal ileum and scope withdrawal time, all affect the clinician's ability to detect polyps and should be scrutinised alongside ADR and PDR. ${ }^{[2,5]}$ Unfortunately, there are no locally derived guidelines or benchmarks for measurement of quality of colonoscopy in South Africa (SA). International guidelines, such as the American Society for Gastrointestinal Endoscopy (ASGE)/American College of Gastroenterology (ACG) Task Force on Colorectal Cancer can be used to benchmark our performance as a unit and that of individual endoscopists. ${ }^{[6]}$

Wits Donald Gordon Medical Centre (WDGMC) in Johannesburg, SA is part of the University of the Witwatersrand academic teaching hospital complex and was the first private academic hospital in SA. In 2006, a formal outpatient endoscopy unit (OEU) was established that currently hosts 14 endoscopists. All endoscopists have medical or surgical specialist training in endoscopy. In this audit, we aimed to describe the clinical profile of patients undergoing colonoscopy at WDGMC and to evaluate the practice of colonoscopy in the OEU by assessing intraprocedural quality indicators.

\section{Methods}

We conducted a prospective, clinical practice audit of colonoscopies performed on adults ( $\geq 18$ years of age) between 1 March 2018 and 28 February 2019 at the WDGMC OEU. Each endoscopist agreed to participate in the audit, and we obtained written informed consent from all patients. The attending nurse collected details of the colonoscopy at the time of the procedure using a standardised data collection sheet (Appendix A: http://samj.org.za/public/sup/14419-a. pdf) and data were imported into REDCap (Research Electronic Data Capture). ${ }^{[7]}$ Bowel preparation prior to colonoscopy was prescribed according to the endoscopist's preference and was not standardised for the OEU. Adequacy of bowel preparation at the time of colonoscopy was assessed by the endoscopist using a non-standardised score, graded as: (i) good; (ii) fair; (iii) poor; and (iv) bad. The variables collected enabled the calculation of caecal intubation rates (CIR) and PDR. We did not record any information on size, grade, histological type, morphology and anatomical location of polyps or detail regarding the technique of removal (biopsy v. endoscopic mucosal resection). To calculate ADR, histological reports were accessed to confirm whether polyps were adenomatous. In the analysis, we further stratified PDR and ADR by sex, age, population group, withdrawal time and bowel preparation. We analysed data overall and per endoscopist if a minimum of 50 colonoscopies were performed during the review period.

\section{Definitions}

CIR: number of colonoscopies where the caecum or terminal ileum was reached, divided by the number of colonoscopies where the intended endpoint was the caecum or terminal ileum; PDR: number of screening colonoscopies in which polyps were detected, divided by the total number of screening colonoscopies; and ADR: number of screening colonoscopies in which an adenoma was detected, divided by the total number of screening colonoscopies.

\section{Benchmarks}

CIR: $\geq 90 \%$ overall, and $\geq 95 \%$ for screening coloscopies; adequate outpatient bowel preparation rate: $\geq 85 \%$; average withdrawal time for negative-result screening colonoscopies: $\geq 6$ minutes; ADR: $\geq 25 \%$ overall ( $\geq 30 \%$ for men and $\geq 20 \%$ for women); ${ }^{[2]}$ PDR: $\geq 40 \%$ for men and $\geq 30 \%$ for women (there is no definitive benchmark for PDR from the ASGE/ACG Task Force or other governing bodies, such as the British Society of Gastroenterology (BSG) or the Joint Advisory
Group on gastrointestinal endoscopy (JAG). However, Williams et al. ${ }^{[8]}$ concluded that a PDR of $\geq 40 \%$ for men and $\geq 30 \%$ for women was the minimum requirement to yield an ADR of $>25 \%$ and $>15 \%$ for men and women, respectively. ${ }^{[7,9]}$

\section{Data analysis}

CIR, PDR and ADR estimates were compared between patient groups by the $\chi^{2}$ test; Fisher's exact test was used for $2 \times 2$ tables. Data analysis was done using SAS version 9.4 for Windows (Microsoft, USA). A $p$-value $<0.05$ was used.

\section{Ethical approval}

The study was approved by the Human Research Ethics Committee (Medical) of the University of the Witwatersrand (ref. no. M171142).

\section{Results}

\section{Demographic characteristics of patients undergoing colonoscopy}

We recruited 1643 patients from 1 March 2018 to 28 February 2019; their demographic characteristics are summarised in Table 1. The mean age of patients was 55.7 (standard deviation (SD) 14.4; range 18 91) years, $\sim 60 \%$ were female and the majority (75.5\%) were white. Although this is an outpatient unit, 9.1\% were hospital inpatients referred for colonoscopy to the OEU.

\section{Indications for colonoscopy}

The most common indications for colonoscopy were screening (41.7\%), polyp surveillance (9.7\%) and cancer surveillance (8.7\%) (Table 2).

\section{Quality indicators for colonoscopy}

Overall and screening CIR, adequacy of bowel preparation and withdrawal time on screening colonoscopy are shown in Table 3.

\begin{tabular}{|c|c|c|}
\hline Characteristic & $\begin{array}{l}\text { All colonoscopies } \\
(N=1643), n(\%)\end{array}$ & $\begin{array}{l}\text { Screening } \\
\text { colonoscopies } \\
(n=686), n(\%)\end{array}$ \\
\hline \multicolumn{3}{|l|}{ Age, years } \\
\hline $18-39$ & $239(14.6)$ & $43(6.3)$ \\
\hline $40-49$ & $266(16.2)$ & $115(16.8)$ \\
\hline $50-59$ & $407(24.8)$ & $204(29.7)$ \\
\hline $60-69$ & $440(26.8)$ & $217(31.6)$ \\
\hline $70-79$ & $248(15.1)$ & $93(13.6)$ \\
\hline$\geq 80$ & $43(2.6)$ & $14(2.0)$ \\
\hline \multicolumn{3}{|l|}{ Sex } \\
\hline Male & $688(41.9)$ & $276(40.2)$ \\
\hline Female & $955(58.1)$ & $410(59.8)$ \\
\hline \multicolumn{3}{|l|}{ Population group } \\
\hline White & $1241(75.5)$ & $543(79.2)$ \\
\hline Indian/Asian & $225(13.7)$ & $74(10.8)$ \\
\hline Black & $131(8.0)$ & $54(7.9)$ \\
\hline Mixed race & $40(2.4)$ & $12(1.7)$ \\
\hline Other & $4(0.2)$ & $2(0.3)$ \\
\hline Missing & $2(0.1)$ & $1(0.1)$ \\
\hline \multicolumn{3}{|c|}{ Outpatient/inpatient status } \\
\hline Outpatient & $1489(90.6)$ & $620(90.5)$ \\
\hline Inpatient & $150(9.1)$ & $64(9.3)$ \\
\hline Missing & $4(0.2)$ & $2(0.3)$ \\
\hline
\end{tabular}




\section{Table 2. Indications for colonoscopy}

\begin{tabular}{ll}
\hline Indication $^{*}$ & $\boldsymbol{n}(\%)(\mathbf{N = 1 6 4 3 )}$ \\
\hline Screening & $686(41.7)$ \\
Polyp surveillance & $160(9.7)$ \\
Cancer surveillance & $142(8.7)$ \\
Change in bowel habits & $135(8.2)$ \\
Investigation of diarrhoea & $108(6.6)$ \\
Rectal bleeding & $93(5.7)$ \\
Anaemia & $83(5.1)$ \\
Abdominal pain & $82(5.0)$ \\
Inflammatory bowel disease surveillance & $75(4.6)$ \\
Inflammatory bowel disease symptoms & $60(3.7)$ \\
Constipation & $16(1.0)$ \\
Other & $21(1.3)$ \\
Missing & $1(0.1)$ \\
${ }^{*}$ More than one indication per procedure is possible. &
\end{tabular}

For screening colonoscopies, PDR and ADR stratified by sex, population group and withdrawal time are described in Table 4. Benchmarks for each quality indicator were included, where available. ${ }^{[2]}$ We demonstrated a $23.7 \%$ increase in PDR and $14.1 \%$ increase in ADR between scopes that had mean withdrawal times of $\geq 6$ minutes and $<6$ minutes. Of the 686 screening colonoscopies performed, 176 polyps/specimens were sent for histological analysis, and in these, 1 malignancy was diagnosed (grade 1 neuroendocrine tumour).

We were able to compare the performance of 10 of the 14 endoscopists who participated in the study - each had completed $>50$ colonoscopies during the study period. All of these endoscopists achieved an overall CIR above the benchmark of $90 \%$; half $(5 / 10)$ met the benchmark of $\geq 95 \%$ for screening colonoscopies; 2 achieved the $\geq 85 \%$ benchmark for adequate outpatient bowel preparation; 3 had a median withdrawal time of $\geq 6$ minutes for negative-result screening colonoscopies; and only 1 met the benchmark of $\geq 40 \%$ and $\geq 30 \%$ for men and women, respectively, for PDR, and $\geq 25 \%$ for ADR.

\begin{tabular}{lll} 
Table 3. Quality indicators & & Benchmark \\
\hline Quality indicator & $n / N(\%)^{*}$ & $\geq 90 \%$ \\
\hline Caecal intubation rate & $1582 / 1631(97.0)$ & $\geq 95 \%$ \\
$\quad$ All colonoscopies & $659 / 684(96.3)$ & - \\
$\quad$ Screening colonoscopies only & & $\geq 85 \%$ \\
Good/fair bowel preparation & $1248 / 1642(76.0)$ & - \\
$\quad$ All colonoscopies & $1155 / 1448(77.6)$ & - \\
$\quad$ Outpatients & $92 / 150(61.3)$ & - \\
$\quad$ Inpatients & & - \\
Withdrawal time on screening & $6.3(4.2-9.3 ; 1.1-43.3)$ & - \\
$\quad$ Time (min.), median (IQR; range) $(n=628)$ & $284 / 628(45.2)$ & $\geq 6$ min. \\
$\quad<6$ min. & $344 / 628(54.8)$ & \\
$\quad \geq 6$ min. & $214 / 628(34.1)$ & \\
$\quad \geq 8$ min. & & \\
$\quad$ Time for negative-result screening colonoscopies (min.), median (IQR; range) $(n=458)$ & $5.7(4.2-9.3 ; 1.1-20.6)$ & \\
IQR $=$ interquartile range. & &
\end{tabular}

Table 4. Polyp and adenoma detection rates for screening colonoscopies

\begin{tabular}{|c|c|c|c|c|c|c|}
\hline & \multicolumn{3}{|c|}{ Polyp detection rate } & \multicolumn{3}{|c|}{ Adenoma detection rate } \\
\hline & $n / N(\%)$ & $p$-value & Benchmark, \% & $n / N(\%)$ & $p$-value & Benchmark, \% \\
\hline Overall & $186 / 685^{*}(27.2)$ & & - & $107 / 686(15.6)$ & & $\geq 25$ \\
\hline \multicolumn{7}{|l|}{ Sex } \\
\hline Male & $100 / 276(36.2)$ & 0.0001 & $\geq 40$ & $56 / 276(20.3)$ & 0.0071 & $\geq 30$ \\
\hline Female & $86 / 409(21.0)$ & & $\geq 30$ & $51 / 410(12.4)$ & & $\geq 20$ \\
\hline \multicolumn{7}{|c|}{ Population group ${ }^{\dagger}$} \\
\hline White & $149 / 542(27.5)$ & 0.76 & - & $83 / 543(15.3)$ & 0.75 & - \\
\hline Indian/Asian & $19 / 74(25.7)$ & & - & $13 / 74(17.6)$ & & - \\
\hline Black & $17 / 54(31.5)$ & & - & $10 / 54(18.5)$ & & - \\
\hline \multicolumn{7}{|l|}{ Withdrawal time } \\
\hline$<6 \mathrm{~min}$. & $40 / 284(14.1)$ & & - & $21 / 284(7.4)$ & & - \\
\hline$\geq 6 \mathrm{~min}$. & $130 / 344(37.8)$ & $\begin{array}{l}<0.0001 \\
\text { (v. }<6 \text { min.) }\end{array}$ & - & $74 / 344(21.5)$ & $\begin{array}{l}<0.0001 \\
\text { (v. }<6 \text { min.) }\end{array}$ & - \\
\hline$\geq 8$ min. $^{*}$ & $97 / 214(45.3)$ & $\begin{array}{l}<0.0001 \\
\text { (v. }<6 \text { min.) } \\
0.080 \\
\text { (v. } \geq 6 \text { min.) }\end{array}$ & - & $56 / 214(26.2)$ & $\begin{array}{l}<0.0001 \\
\text { (v. }<6 \mathrm{~min} .) \\
0.20 \\
\text { (v. } \geq 6 \text { min.) }\end{array}$ & - \\
\hline
\end{tabular}




\section{Discussion}

This preliminary clinical audit was our first attempt to evaluate the practice of colonoscopy in the $\mathrm{OEU}$, with results proving promising for the future performance of the unit. It was expected that the majority of the scopes would be for screening (41.7\%), surveillance for polyps (9.7\%) and cancer (8.7\%), as some of the endoscopists perform screening colonoscopies as part of the standard requirements for liver transplantation (WDGMC runs the largest liver transplant programme and has one of the largest oncology units in SA). Additionally, international guidelines recommend screening colonoscopy for those $>50$ years of age. ${ }^{[2]}$ Therefore, it is reasonable that, when compared with an audit from Charlotte Maxeke Johannesburg Academic Hospital (CMJAH) and international audits from Canada, the UK and Greece, the proportion of screening colonoscopies done at WDGMC was almost double (WDGMC: $41.7 \%$ v. $9.7 \%-28.7 \%){ }^{[1,5,10-12]}$

When assessing the key quality indicators of screening colonoscopies, results showed that our PDR (27.2\%) and ADR (15.6\%) were low compared with international benchmarks and published data from high-income countries. These studies reported PDRs between $32.1 \%$ and $59.7 \%$, and ADRs between $27.1 \%$ and $54.0 \%{ }^{[1,10,13-15]}$ The obvious explanation might be that our patient profile is different, requiring locally derived, population-appropriate benchmarks for South Africans and, preferably, the sub-Saharan African (sSA) region. While a small proportion of patients in this clinical audit were black Africans, it is noteworthy that PDRs and ADRs for this group were similar to those of other population groups, despite the historical belief that black Africans 'do not get polyps. ${ }^{[16]}$ When compared with neighbouring countries, a study from Harare, Zimbabwe reported polyps in 5\% of black Zimbabweans compared with $8 \%$ of white Zimbabweans. ${ }^{[17]}$ Studies from Zambia and Nigeria reported overall PDRs of $10 \%$ and $7.4 \%$, respectively. ${ }^{[18,19]}$ Unfortunately, none of the studies from our region reported ADRs, as very few of the colonoscopies performed were true screening scopes. For the same reason, these PDRs must be interpreted with caution. The audit from CMJAH reported a PDR of $25.2 \%$, which is similar to our PDR of $27.2 \% \cdot{ }^{[5]}$ Overall, the higher PDR reported for different sites in Johannesburg - the largest and wealthiest urban metropole in the country - might reflect relative affluence, and evidence of an epidemiological sociodemographic transition from rural to urban living for its residents, with associated dietary and lifestyle changes. SA might be at a more advanced stage of this transition than other sSA countries. Interestingly, it is well documented that African Americans, who have similar genetic origins to black Africans, have a higher prevalence of polyps than their white counterparts, suggesting a geneenvironment interaction that might alter clinical phenotypes. ${ }^{[20]}$

Alternatively, we could also question the quality of our clinical practice. Average withdrawal times $>6$ minutes were significantly associated with higher PDR/ADR and our withdrawal time on negativeresult screening colonoscopies was just under the recommended target of $\geq 6$ minutes. Although some endoscopists challenge the association between withdrawal times and PDR/ADR (as increasing withdrawal time alone will not improve an ADR/PDR that is already adequate), data suggest that longer withdrawal times are strongly associated with an increase in PDR and ADR, particularly when endoscopists do not achieve accepted benchmarks. ${ }^{[1,13,19,21]}$

Another factor that could have affected our PDR/ADR was the adequacy of our outpatient bowel preparation, which was below the ASGE/ACG Task Force benchmark of $\geq 85 \%$. Interestingly, our results showed that inadequate bowel preparation yielded similar PDRs and ADRs to adequate bowel preparation, which could indicate that we are 'over-calling' poor bowel preparation as opposed to it actually being inadequate. ${ }^{[1,2]}$ This could be owing to our clinicians not prescribing a standardised bowel preparation product or not using the same bowel preparation assessment tool when reporting the adequacy of this metric.

Despite not meeting the benchmark for bowel preparation, CIR was above the ASGE/ACG Task Force recommendation of $\geq 90 \%$ for all colonoscopies and $\geq 95 \%$ for screening colonoscopies. International audits from Canada, the UK and New Zealand report CIRs on par with ours. ${ }^{[1,11,13]}$ It must be noted that in our calculation of CIR, we accounted for the starting intention of the colonoscopy, whereas other studies could have used the total number of screening colonoscopies, regardless of the intention. Other audits from SA report variable CIRs, both above and below the ASGE/ACG benchmark. ${ }^{[5,22]}$

As part of the continuation of this audit in years to come, we shared our overall results with all healthcare workers in the OEU, which stimulated productive discussion regarding areas for improvement and additional variables for inclusion. For example, we will implement the Harefield cleansing scale for assessing bowel preparation. ${ }^{[23]}$ For results per endoscopist, the clinicians requested open sharing of their data in an anonymised format. Each endoscopist also received a confidential report of their performance metrics. The published literature suggests that confidential feedback to each individual on their metrics, without unit-wide intervention, makes a difference to PDR and withdrawal time. ${ }^{[24-26]}$ On this basis, the endoscopists at WDGMC agreed to use results from this audit as a baseline for comparison in the next annual audit. The annual report is accessible in the public domain.

\section{Study limitations}

This audit is limited by the patient pool, as it reflects an urban, singlecentre experience of health-insured individuals, and our findings may not be generalisable. The sample may be biased because the OEU screens all patients receiving liver transplants at WDGMC. Therefore, the screening population may not be average-risk asymptomatic individuals. There are no national guidelines or benchmarks for South Africans, or for different population groups within SA, which make interpreting low PDRs and ADRs difficult.

\section{Conclusions}

The audit of the WDGMC OEU revealed that $77.6 \%$ of outpatients had adequate bowel preparation, the CIR was $97.0 \%$ overall, and $96.3 \%$ for screening colonoscopies. The median withdrawal time for negative-result screening colonoscopies was 5.7 minutes. For screening colonoscopies, the PDR and ADR were $27.6 \%$ and $15.6 \%$, respectively, which are lower than benchmarks from HIC regions with a 3-fold higher incidence of CRC, yet relatively higher than rates reported from other sSA countries. While short withdrawal times might affect the PDR and ADR, the validity of using externally derived high-income population benchmarks in SA deserves scrutiny. Given there are no standardised national benchmarks and guidelines on colonoscopy in SA, we hope these data will contribute to developing local guidelines. Annual auditing of clinical practice, and these data thus being available in the public domain, will be standard of care in our OEU, therefore making this year's audit a baseline for longitudinal observation and assessing the impact of interventions, as highlighted in our recommendations.

\section{Recommendations}

The clinicians have agreed to standardise education of patients regarding bowel preparation (with input from clinicians who achieve 
good bowel preparation rates) on the choice of bowel preparation and the use of a validated bowel preparation score. ${ }^{[27]}$ Although adequate bowel preparation may seem straightforward, increasing patient adherence may incur a cost, such as employing a nurse educator who would be responsible for proper education of patients. ${ }^{[28]}$ Furthermore, increasing withdrawal time should be strongly considered as a straightforward and relatively low-cost intervention. Due to the resource-intense nature of recording histological results for calculation of the ADR, the creation of an average adenoma-to-polyp detection rate quotient for the OEU could be cost-effective and useful in determining ADR from PDR, without needing these results. This will be feasible in time, as data from each annual audit can be used as a local reference.

\section{Declaration. None.}

Acknowledgements. We would like to thank Sister Gladys Kgabage and her team at the WDGMC OEU for their contribution to the study.

Author contributions. CB: wrote the first draft of the paper, contributed to the revision, and edited the final draft of the paper; $\mathrm{PB}, \mathrm{DB}, \mathrm{BB}, \mathrm{JD}, \mathrm{NH}$, CJ, AM, JO, JR, MS, DS, DL: contributed to data collection and edited the final draft of the paper; GK: supervised data collection by the OEU staff and contributed to data collection; PG: contributed to planning and executing the statistics, and edited revisions and the final draft of the paper; HE: contributed to editing the drafts, the revisions and the final draft of the paper; JF: contributed to conceptualising the study, edited the first draft, subsequent revisions and final version of the paper; KK: conceptualised the study, contributed to the revision, contributed to data collection and edited the final draft of the paper.

Funding. Funding was provided by the WDGMC.

Conflicts of interest. None.

1. Gavin DR, Valori RM, Anderson JT, Donnelly MT, Williams JG, Swarbrick ET. The national colonoscopy audit: A nationwide assessment of the quality and safety of colonoscopy in the UK. Gut 2013;62(2):242-249. https://doi.org/10.1136/gutjpl-2011-301848

2. Rex DK, Schoenfeld PS, Cohen J, et al. Quality indicators for colonoscopy. Gastrointest Endosc 2015;81(1):31-53. https://doi.org/10.1016/j.gie.2014.07.058

3. Anderson JC, Butterly LF. Colonoscopy: Quality indicators. Clin Transl Gastroenterol 2015;6(2):e77. https://doi.org/10.1038/ctg.2015.5

4. Leslie A, Carey FA, Pratt NR, Steele RJC. The colorectal adenoma-carcinoma sequence. Br J Surg 2002;89(7):845-860. https://doi.org/10.1046/j.1365-2168.2002.02120.x

5. Mahomed AD, Cremona E, Fourie C, et al. A clinical audit of colonoscopy in a gastroenterology unit at a tertiary teaching hospital in South Africa. S Afr Gastroenterol Rev 2012;10(3).
6. Cabebe EC, Espat J. What are the US multi-society task force on colorectal cancer guidelines for colorectal cancer screening tests? Medscape 2018. https://www.medscape.com/answers/2500006-108967/what-arethe-us-multi-society-task-force-on-colorectal-cancer-guidelines-for-colorectal-cancer-screening-tests (accessed 9 October 2020).

7. Harris PA, Taylor R, Thielke R, Payne J, Gonzalez N, Conde JG. Research Electronic Data Capture (REDCap) - a metadata-driven methodology and workflow process for providing translational research informatics support. J Biomed Inform 2009;42(2):377-381. https:// 1 oi.org/10.1016/ji.jbi.2008.08.010

8. Williams JE, Holub JL, Faigel DO. Polypectomy rate is a valid quality measure for colonoscopy: Results Williams JE, Holub JL, Faigel DO. Polypectomy rate is a valid quality measure for colonoscopy: Results
from a national endoscopy database. Gastrointest Endosc 2012;75(3):576-582. https://doi.org/10.1016/j. giem a nationa 2011.12 .012

gie.2011.12.012 Williams JE, Le TD, Faigel DO. Polypectomy rate as a quality measure for colonoscopy. Gastrointest Endosc 2011;73(3):498-506. https://doi.org/10.1016/j.gie.2010.08.008

10. Karamaroudis S, Stamou A, Vorri SC, et al. Monitoring of colonoscopy quality indicators in an academic endoscopy facility reveals adherence to international recommendations. Ann Transl Med 2018;6(13). https://doi.org/10.21037/atm.2018.03.34

11. Armstrong D, Hollingworth R, Macintosh D, et al. Point-of-care, peer-comparator colonoscopy practice audit: The Canadian Association of Gastroenterology quality program - endoscopy. Can J Gastroenterol 2011;25(1):13-20. https://doi.org/10.1155/2011/320904

12. De Jonge V, Sint Nicolaas J, Lalor EA, et al. A prospective audit of patient experiences in colonoscopy using the global rating scale: A cohort of 1187 patients. Can J Gastroenterol 2010;24(10):607-613. https:// doi.org/10.1155/2010/724924

3. Fraser AG, Gamble GD, Rose TR, Dunn JP. Colonoscopy audit over 10 years - what can be learnt? N Z Med J 2013;126(1382):25-35.

4. Lee TJW, Rutter MD, Blanks RG, et al. Colonoscopy quality measures: Experience from the NHS bowel cancer screening programme. Gut 2012;61(7):1050-1057. https://doi.org/10.1136/gutjnl-2011-300651

15. Rees CJ, Thomas Gibson S, Rutter MD, et al. UK key performance indicators and quality assurance standards for colonoscopy. Gut 2016;65(12):1923-1929. https://doi.org/10.1136/gutinl-2016-312044

6. Segal I, Cooke SA, Hamilton DG, Ou Tim L. Polyps and colorectal cancer in South African Blacks. Gut 1981;22(8):653-657. http://doi.org/10.1136/gut.22.8.653

17. Katsidzira L, Gangaidzo IT, Mapingure MP, Matenga JA. Retrospective study of colorectal cancer in Zimbabwe: Colonoscopic and clinical correlates. World J Gastroenterol 2015;21(8):2374-2380. https:// doi.org/10.3748/wjg.v21.i8.2374

18. Osinowo A, Lawal O, Lesi O, Olajide T, Adesanya A. Audit of colonoscopy practice in Lagos University Teaching Hospital. J Clin Sci 2016;13(1):29. https://doi.org/10.4103/1595-9587.175487

19. Kayamba V, Nicholls K, Morgan C, Kelly P. A seven-year retrospective review of colonoscopy records from a single centre in Zambia. Malawi Med J 2018;30(1):17-21. https:///doi.org/10.4314/mmj.v30i1.4

from a single centre in Zambia. Malawi Med J 2018;30(1):17-21. https://doi.org/ $/ 0.4314 / \mathrm{mm}$ j.v30i1.4
20. Lieberman D, Holub J, Moravec M, Eisen G, Peters D, Morris C. Prevalence of colon polyps detected Lieberman D, Holub J, Moravec M, Eisen G, Peters D, Morris C. Prevalence of colon polyps detected
by colonoscopy screening in asymptomatic black and white patients. JAMA 2008;300(12):1417-1422. by colonoscopy screening in asymptoma

21. Calderwood AH, Jacobson BC. Colonoscopy quality: Metrics and implementation. Gastroenterol Clin North Am 2013;42(3):599-618. https://doi.org/10.1016/.gtc.2013.05.005

22. Benamro A, Bruce JL, Clarke DL. An electronic colonoscopy record system enables detailed quality assessment and benchmarking of an endoscopic service. S Afr Med J 2015;105(12):1061. https://doi org/10.7196/SAMJ.2015.v105i12.10115

23. Halphen M, Heresbach D, Gruss H-J, Belsey J. Validation of the Harefield cleansing scale: A tool for the evaluation of bowel cleansing quality in both research and clinical practice. Gastrointest Endosc 2013;78(1):121-131. https://doi.org/10.1016/j.gie.2013.02.009

24. Lin OS, Kozarek RA, Arai A, et al. The effect of periodic monitoring and feedback on screening colonoscopy withdrawal times, polyp detection rates, and patient satisfaction scores. Gastrointest Endos 2010;71(7):1253-1259. https://doi.org/10.1016/.j.gie.2010.01.017

25. Gurudu SR, Boroff ES, Crowell MD, et al. Impact of feedback on adenoma detection rates: Outcomes of quality improvement program. J Gastroenterol Hepatol 2018;33(3):645-649. https://doi.org/10.1111/ jgh. 13984

26. Nielsen $\mathrm{AB}$, Nielsen $\mathrm{OH}$, Hendel J. Impact of feedback and monitoring on colonoscopy withdrawal times and polyp detection rates. BMJ Open Gastroenterol 2017;4(1):e000142. https://doi.org/10.1136/ bmigast-2017-000142

27. Kastenberg D, Bertiger G, Brogadir S. Bowel preparation quality scales for colonoscopy. World J Gastroenterol 2018;24(26):2833-2843. https://doi.org/10.3748/wjg.v24.i26.2833

28. Rosenfeld G, Krygier D, Enns RA, Singham J, Wiesinger H, Bressler B. The impact of patient education on the quality of inpatient bowel preparation for colonoscopy. Can J Gastroenterol 2010:24(9):543-546. https://doi.org/10.1155/2010/718628

Accepted 3 June 2020. 